\title{
The Inspection Time and Over-Claiming Tasks as Predictors of MBA Student Performance
}

Bryan Pesta

Cleveland State University, b.pesta@csuohio.edu

Peter J. Poznanski

p.poznanski@csuohio.edu

Follow this and additional works at: https://engagedscholarship.csuohio.edu/bus_facpub

Part of the Organizational Behavior and Theory Commons

How does access to this work benefit you? Let us know!

\section{Publisher's Statement}

NOTICE: this is the author's version of a work that was accepted for publication in Personality and Individual Differences. Changes resulting from the publishing process, such as peer review, editing, corrections, structural formatting, and other quality control mechanisms may not be reflected in this document. Changes may have been made to this work since it was submitted for publication. A definitive version was subsequently published in Personality and Individual Differences, 46, 2, (2009); 10.1016/j.paid.2008.10.005

\section{Original Published Citation}

Pesta, B., Poznanski, P. (2009). The inspection time and over-claiming tasks as predictors of MBA student performance. Personality and Individual Differences, 46(2), pp. 236-240.

This Article is brought to you for free and open access by the Monte Ahuja College of Business at EngagedScholarship@CSU. It has been accepted for inclusion in Business Faculty Publications by an authorized administrator of EngagedScholarship@CSU. For more information, please contact library.es@csuohio.edu. 


\title{
The inspection time and over-claiming tasks as predictors of MBA student performance
}

\author{
Bryan J. Pesta ${ }^{\mathrm{a},}$, Peter J. Poznanski ${ }^{\mathrm{b}}$ \\ ${ }^{2}$ Department of Management, Cleveland State University, 2121 Euclid Avenue, Cleveland, Ohio 44115, USA \\ ${ }^{b}$ Department of Accounting, Cleveland State University, 2121 Euclid Avenue, Cleveland, Ohio 44115, USA
}

\section{Introduction}

Over a century of academic research has established the relationship between general mental ability (GMA) and success in life, whether operationalized as educational achievement, income levels, or job performance (see, e.g., Gottfredson, 2004; Neisser et al., 1996; Schmidt \& Hunter, 1998). Most of these studies measured GMA via standardized, paper and pencil intelligence (IQ) tests. More recently, researchers have explored whether measures of basic information processing ability (i.e., "elementary cognitive tasks," ECTs) can also predict real-world outcomes (see, e.g., Luo Thompson, \& Detterman, 2006; Rohde \& Thompson, 2007). The goal of the present study was to explore whether ECTs would possess both criterion and incremental validity as predictors of a highlevel cognitive outcome-student performance in an MBA program.

ECTs represent a range of tasks where subjects perform trivially simple cognitive acts, like selecting which of two rapidly-presented lines was longer (see Jensen, 1998; Jensen, 2006, for reviews). Although face-invalid as measures of mental ability. ECTs nonetheless produce large individual differences which correlate about 0.50 with traditional IQ tests (Grudnik \& Kranzler, 2001; Kranzler \& Jensen, 1989; Sheppard \& Vernon, 2008). Linking intelligence and ECT performance is the hypothesis that the former may be some global index of individual differences in the efficiency with which brains process information, as measured reliably by the latter (see, e.g.,

\footnotetext{
- Corresponding author, Tel.: +1 2166874749.

E-mail addresses: b.pesta@csuohio.edu, bpesta22@cs.com (B.J. Pesta).
}

Jensen, 1998, 2006). Further connecting global intelligence to basic cognitive and neurological processes are recent findings that IQ scores correlate with overall brain volume (McDaniel, 2005: Posthuma et al., 2002), nerve conduction velocity and event related potentials (De Pascalis, Varriale, \& Matteoli, 2007), glucose metabolism rates (Haier, Siegel, Tang, Abel, \& Buchsbaum, 1992), and even body symmetry (Prokosch, Yeo, \& Miller, 2005).

To date, ECTs have been used mainly in basic research geared toward understanding the structure of intelligence. Notable exceptions include using ECTs to predict neuropathology, rates of cognitive aging, and academic performance (reviewed in detail by Jensen, 2006). Luo et al. (2006), for example, showed that ECTs possess criterion and incremental validity (over standardized IQ tests) as predictors of scholastic achievement among 6-19 year olds (but see Rohde \& Thompson, 2007, for the lack of incremental validity of ECTs predicting SAT scores and grades for young adults). The present study extends upon prior research in this area. Here we focus on adults-graduate MBA students-and rely on two methodologically dissimilar ECTs: the inspection time (IT) and over-claiming tasks.

The IT task measures the amount of information people can absorb and process accurately when that information is presented very briefly (Burns \& Nettelbeck, 2002). On any trial subjects first see two vertical lines on a computer screen, joined at the top by a horizontal line (called the "Pi" stimulus, because it resembles the Greek letter $\mathrm{Pi}$ ). One of the lines, selected randomly, appears longer than the other. The task is simply to indicate which of the two lines in the Pi stimulus is longer. Only response accuracy is recorded, as 
subjects are instructed to take as much time as they need to make their decisions. The Pi stimulus, however, is presented very briefly (sometimes as fast as $10 \mathrm{~ms}$ ), and is then followed by a pattern mask (e.g., lightening bolts appearing in the same area as the two lines). The pattern mask is used to prevent further iconic processing of the Pi stimulus (see, e.g., Luciano, Leisser, Wright, \& Martin, 2004, for an example of the lightning bolt mask).

The key measure is the subject's accuracy across differing display durations. IT is typically operationalized as the shortest duration Pi can be displayed where subjects still achieve some desired level of accuracy. Scores on the IT task correlate about 0.50 with paper and pencil measures of IQ (for meta-analytic reviews see, Grudnik \& Kranzler, 2001 Kranzler \& Jensen, 1989).

Our second ECT, the over-claiming task, measures simple familiarity with general world-knowledge concepts (Paulhus \& Harms, 2004). Although this task is not a prototypical ECT, we included it here because of its ability to measure familiarity (i.e., a non-specific feeling that a stimulus is not new; Jacoby, 1992). Familiarity is thought to be an automatic mental process; one that occurs without conscious control (see, e.g., Hasher \& Zacks, 1979; Yonelinas \& Jacoby, 1996). The over-claiming task measures familiarity by presenting subjects with the name of a moderately famous historical figure, scientific term, or other concept. Participants merely rate how familiar they are with the concept, on a 1 ("I never heard of it") to 5 ("I am very familiar with it") Likert scale. Foils are included which allow the tester to adjust each person's familiarity score for any tendency to "over-claim." As with the IT task, corrected familiarity ratings on the over-claiming task correlate about 0.50 with scores on paper and pencil measures of GMA (Paulhus \& Harms, 2004; see Williams, Paulhus, \& Nathanson, 2002, for evidence that familiarity in the over-claiming task is an automatic process).

Following Luo et al. (2006), and Rohde and Thompson (2007), we explored whether ECTs would possess criterion and incremental validity for a high-level cognitive outcome-student performance in an MBA program. Participants were final-semester MBA students. They completed the wonderlic personnel test (WPT) and then the IT and over-claiming tasks. These variables (together with graduate management admissions test (GMAT), scores) were then used to predict final grade point averages (GPAs), and scores on a capstone assessment exam (a content valid test of management knowledge, used for program assessment and accreditation, as described below). We tested two hypotheses:

Hypothesis 1: Both the IT and over-claiming ECTs will possess criterion validity for MBA grades and capstone exam scores.

Hypothesis 2: $\quad$ Both the IT and over-claiming ECTs will show incremental validity over IQ and GMAT scores in predicting MBA grades and capstone exam scores.

\section{Method}

\subsection{Participants and materials}

Participants were final-semester MBA students enrolled in the program's capstone course for the calendar year. These included 56 male and 60 female students, with a mean age of 28.8 $(S D=5.06)$ years. Students gave written consent before starting the project, and received participation credit after completing both phases (the IQ test and the ECT tasks) of the study. We also coded GMAT scores from student transcripts, as well as scores on the MBA capstone exam (although our college did not administer the exam in the summer, which reduced the sample size for just this variable to $n=84$ ).
The capstone exam was developed by our college for use in program assessment and accreditation. It comprises 81 multiplechoice items, covering all functional areas of business (i.e., management, marketing, finance, accounting, operations, and information systems). Students take the exam in their graduating semester, and it produces internal consistency reliabilities in the upper 0.70 s across administrations. Faculty structured the exam to have a high degree of content validity, as each department within the college decided which material was most critical, and wrote test items to cover that content. In this regard, the entire college faculty had input into developing the exam, and it represents a content valid test of what students should know after graduating from an MBA program.

GMA was measured with the WPT (Form IV, Wonderlic \& Associates, 2002). The WPT is a standardized, paper and pencil exam, with a population mean of 22 and a standard deviation of 7 . Research shows reliabilities for the WPT ranging from 0.82 to 0.94 (Geisinger, 2001). The test manual reports strong correlations between the WPT and other standardized IQ tests (Wonderlic \& Associates, 2002; see Table 9, p. 34). In addition, McKelvie (1989) reports validities between 0.30 and 0.45 for the WPT predicting (undergraduate student) grades.

\subsection{Procedure}

We administered the 12 min version of the WPT in class. Students later completed the ECTs in a computer lab. Instructions for the ECTs were presented onscreen, and included an overview of each task, with sample trials illustrating how participants should respond. For both ECTs, students were told to take as much time as they needed, focusing only on responding accurately.

The IT task was a modified version of that used by Luciano et al. (2004). A trial began with a fixation cross, which showed students where to direct their attention. The fixation cross was followed by the Pi stimulus (i.e., two vertical lines of different length, joined at the top by a horizontal line), which remained onscreen for varying amounts of time across trials. In general, the duration increased when subjects made errors on previous trials (i.e., making the next trial easier) and decreased when subjects responded correctly on previous trials (i.e., making the next trial more difficult).

On every trial, the Pi stimulus was masked with a "lightening bolt" image to prevent further mental processing of the lines after their display duration had expired. A blank computer screen followed the mask. Students then pressed the " $z$ " key on the keyboard if they thought the left line was longer than the right or the " $\mathrm{m}$ " key if they thought the opposite. The primary measure in the IT task was not speed of response, but the average display duration of the Pi stimulus for each subject across 15 reversals (i.e., trials where the Pi stimulus changed in duration, because the participant got the previous trial right or wrong; see Pesta \& Poznanski, 2008, for a full account of how reversals are used to estimate IT). Lower values for IT indicated better performance. For example, consider two subjects with IT values of 33 and $66 \mathrm{~ms}$, respectively. Whereas the first subject accurately judged line lengths even when the lines were displayed for only 33/1000 of a second, the second subject needed twice as much time staring at the lines (i.e., 66/1000 of a second) to be as accurate as the first subject. Hence, the first subject performed better than did the second.

The over-claiming task was also computer administered. A trial began by displaying a concept (e.g., "The Waste Land"), followed by a Likert scale. Students used the number pad to rate how familiar they were with the concept on a 1 ("I've never heard of it") to 5 ("I am very familiar with it") scale. Some of the concepts presented in the task were fictitious (e.g., "Biosexual"). Having students rate both real and fictitious items allowed for the calculation of corrected familiarity (i.e., sensitivity) scores for each participant. 
Primary measures for the over-claiming task included: (1) mean confidence ratings for real and not-real items. (2) The proportion of real items (out of 60 ) the subject claimed to be familiar with (indicated by ratings $>1.0$ for each concept). This value is the hit rate. (3) The proportion of not-real items (out of 30) the subject incorrectly claimed were familiar. This value is the false alarm rate. Sensitivity in the over-claiming task is then computed both as the difference in confidence ratings (Likert scale) for real versus notreal items, and as the difference between hits and false alarms (proportions). Research on the over-claiming task reveals that sensitivity correlates about 0.50 with paper and pencil IQ tests (Paulhus \& Harms, 2004).

\section{Results}

\subsection{Descriptive statistics and simple correlations}

Table 1 shows descriptive statistics and simple correlations for the study's key variables. The last variable in the table is an ECT component score resulting from a principal component analysis on (1) inspection time, (2) the mean difference in ratings for real versus not-real items, and (3) the proportion of hits minus the proportion of false alarms. The component score explained $68 \%$ of the variance in the three variables.

All correlations in Table 1 were significant. For MBA grades, the best prediction came from the GMAT $(r=0.53)$, followed by the WPT $(r=0.44)$, and then the ECTs $(r=0.33$ for the component score). For MBA capstone exam scores, the ECT component emerged as (nominally) the best predictor $(r=0.50)$, followed by the GMAT $(r=0.47)$, and then the WPT $(r=0.46)$. Note, finally, that the WPT correlated moderately with the GMAT $(r=0.56)$, and with the ECT component $(r=0.61)$.

\subsection{Hypothesis tests}

Hypothesis 1 was that both the IT and over-claiming ECTs would possess criterion validity for predicting MBA grades and MBA capstone exam scores. Table 1 supports this hypothesis. Validity coefficients for the IT and over-claiming tasks ranged from 0.24 to 0.50 . An ECT component score derived from these measures explained $11 \%$ of the variance in MBA grades, and $25 \%$ of the variance in MBA exam scores. In context, ECTs predicted exam scores as well as did either the GMAT or the WPT. However, ECTs were weaker predictors of grades relative to these other two variables.

To further test Hypothesis 1, we split the sample into two, equal-sized groups based on ECT component scores. The first group contained all students performing above the median on the ECTs, and the second group contained all students performing at the median or worse. Table 2 shows how these groups compared on the standardized exams, MBA grades and MBA capstone exam.
The biggest difference in the table was for the WPT ( $d=1.26)$, replicating prior research on the strong relationship between ECTs and standardized measures of IQ (see, e.g., Grudnik \& Kranzler, 2001 Kranzler \& Jensen, 1989). Also of note is the moderate effect size $(d=0.57)$ for the ECT groups on GMAT scores. This finding is consistent with more recent literature showing that standardized admissions exams also measure general mental ability (see, e.g., Frey \& Detterman, 2004; Koenig, Frey, \& Detterman, 2008).

Turning to the criterion measures, a strong effect existed on the MBA exam $(d=0.79)$, where the best-performing ECT group averaged $5.32 \%$ points higher ( 4.3 more items correct out of 81 total items) on the exam, compared with the worst performing ECT group. Finally, the effect size for grades $(d=0.57)$ was moderate, again favoring the best-performing ECT group. On balance, the data in Tables 1 and 2 support the hypotheses that ECTs possess criterion validity for predicting measures of academic performance.

Hypothesis 2 was that the ECTs would show incremental validity over both the GMAT and the WPT in predicting MBA grades and capstone exam scores. We tested $\mathrm{H} 2$ with hierarchical regressions, as shown in Table 3. Step 1 included the GMAT and WPT scores, followed by the ECT component score in step 2. Looking first at MBA grades, both the GMAT $(\beta=0.419)$ and the WPT $(\beta=0.203)$ were significant at step 1 , explaining $31 \%$ of the variance. In step 2 , however, only the GMAT remained a significant predictor $(\beta=0.413)$. Neither the WPT $(\beta=0.165)$, nor the ECT scores $(\beta=0.069)$ were able to explain unique variance in grades. The percentage of variance explained at step 2 was $32 \%$.

A different pattern emerged for the MBA exam scores (right side of Table 3$)$. Although both the GMAT $(\beta=0.310)$ and the WPT ( $\beta=0.286$ ) were significant at step 1 , adding the ECT component at step 2 produced a significant beta weight of 0.320 , even after controlling for the GMAT and the WPT. Further, controlling for ECTs attenuated the validity of the WPT to non-significance ( $\beta=0.107$, a $63 \%$ reduction relative to step 1 ). The percentage of variance explained at step 2 for capstone exam scores was $34 \%$.

Given mixed results across MBA grades and exam scores, we opted to run the regressions again by separating the IT task from the over-claiming task. The latter correlated substantially higher with the WPT and the GMAT than did the former in Table 1. As such, we wanted to determine whether the failure of the ECT component to uniquely predict grades was due to either the IT or the overclaiming task data (or both). These data also appear in Table 3.

The IT task produced incremental validity for both grades ( $\beta=-0.200$; higher numbers on IT indicate poorer performance) and exam scores $(\beta=-0.207)$. The change in variance explained at step 2 ( $4 \%$ in both cases) was also significant. Hence, the IT task, by itself, showed incremental validity over both the GMAT and the WPT. Turning to the over-claiming task predicting grades, step 2 showed essentially no incremental validity $(\beta=-0.008)$, once both GMAT and WPT scores were in the equation. The failure of the over-claiming task to explain unique variance in grades likely also

Table 1

Descriptive statistics and simple correlations among the study variables.

\begin{tabular}{|c|c|c|c|c|c|c|c|c|c|c|}
\hline Variable & $M$ & $S D$ & 1 & 2 & 3 & 4 & 5 & 6 & 7 & 8 \\
\hline 1. Wonderlic IQ & 23.33 & 5.98 & $-4=$ & & & & & & & \\
\hline 2. GMAT score & 480.54 & 89.89 & 0.56 & - & & & & & & \\
\hline 3. MBA grades & 3.50 & 0.28 & 0.44 & 0.53 & - & & & & & \\
\hline 4. MBA exam (\%) & 57.89 & 8.94 & 0.46 & 0.47 & 0.36 & - & & & & \\
\hline 5. Inspection time (MS) & 107.50 & 66.77 & -0.23 & -0.24 & -0.33 & -0.33 & - & & & \\
\hline 6. Real - not-real & 1.14 & 0.78 & 0.64 & 0.40 & 0.30 & 0.50 & -0.33 & - & & \\
\hline 7. Hits - false alarms (\%) & 0.24 & 0.23 & 0.54 & 0.32 & 0.24 & 0.38 & -0.25 & 0.87 & - & \\
\hline 8 ECT component score & 0.00 & 1.00 & 0.61 & 0.39 & 0.33 & 0.50 & -0.52 & 0.95 & 0.93 & - \\
\hline
\end{tabular}

Both the real - not-real, and the hits - false alarms variables are difference scores (on confidence ratings and proportion-familiar data, respectively) derived from the overclaiming task. The ECT component score included IT and the two over-claiming task variables. $N=116$ for all variables except MBA exam ( $n=84$ ). All correlations in the table are significant (the critical value of $r$ for $N=116$ is 0.19 , and for $n=84$, is 0.22 ). 
Table 2

Mean and standard deviation wonderlic, GMAT scores, MBA grades, and MBA capstone exam scores, by the best and worst performing students on the elementary cognitive tasks.

\begin{tabular}{lllll}
\hline \multicolumn{6}{l}{ Group ECT performance } & & & \\
\hline Variable & Best & Worst & Difference & Effect Size $^{\text {a }}$ \\
\hline Wonderlic IQ & $26.52(4.71)$ & $20.14(5.41)$ & $6.38^{*}$ & 1.26 \\
GMAT score & $504.14(88.4)$ & $454.72(85.0)$ & $49.42^{*}$ & 0.57 \\
MBA grades & $3.58(0.24)$ & $3.43(0.29)$ & $0.15^{*}$ & 0.57 \\
MBA exam \% & $49.49(7.20)$ & $44.17(6.30)$ & $5.32^{*}$ & 0.79 \\
\hline
\end{tabular}

Standard deviations are in parentheses. Sample sizes were $n=58$ per group, except with the MBA exam, where $n=42$ per group.

a Cohen's $d$.

Table 3

Incremental validity of elementary cognitive tasks-over GMAT and IQ scores for predicting MBA grades and MBA capstone exam scores.

\begin{tabular}{|c|c|c|c|c|}
\hline \multirow[t]{2}{*}{ Variable } & \multicolumn{2}{|c|}{ MBA grades } & \multicolumn{2}{|c|}{ MBA exam } \\
\hline & Step $1 \beta$ & Step $2 \beta$ & Step $3 \beta$ & Step $4 \beta$ \\
\hline \multicolumn{5}{|l|}{ ECT component } \\
\hline GMAT scores & $0.419^{b}$ & $0.413^{b}$ & $0.310^{\mathrm{b}}$ & $0.286^{b}$ \\
\hline Wonderlic IQ & $0.203^{b}$ & 0.165 & $0.286^{\mathrm{b}}$ & 0.107 \\
\hline ECT component & - & 0.069 & - & $0.320^{\mathrm{b}}$ \\
\hline$R^{2}=\theta^{2}=4$ & $0.31^{\mathrm{b}}$ & $0.32^{\mathrm{b}}$ & $0.28^{b}$ & $0.34^{\mathrm{b}}$ \\
\hline$\Delta R^{2}$ & & 0.01 & & $0.06^{b}$ \\
\hline \multicolumn{5}{|c|}{ Inspection time only } \\
\hline GMAT scores & $0.419^{b}$ & $0.386^{\mathrm{b}}$ & $0.310^{\mathrm{b}}$ & $0.277^{b}$ \\
\hline Wonderlic IQ & $0.203^{b}$ & 0.175 & $0.286^{\mathrm{b}}$ & $0.257^{b}$ \\
\hline Inspection time & - & $-0.200^{b}$ & - & $-0.207^{b}$ \\
\hline & $0.31^{\mathrm{b}}$ & $0.35^{\mathrm{b}}$ & $0.28^{b}$ & $0.32^{\mathrm{b}}$ \\
\hline$\Delta R^{2}$ & & $0.04^{\mathrm{b}}$ & & $0.04^{b}$ \\
\hline \multicolumn{5}{|c|}{ Over-claiming only } \\
\hline GMAT scores & $0.419^{b}$ & $0.419^{b}$ & $0.310^{\mathrm{b}}$ & $0.300^{b}$ \\
\hline Wonderlic IQ & $0.203^{b}$ & $0.208^{b}$ & $0.286^{\mathrm{b}}$ & 0.127 \\
\hline Over-claiming & - & -0.008 & - & $0.271^{b}$ \\
\hline$R^{2}$ & $0.31^{\mathrm{b}}$ & $0.31^{\mathrm{b}}$ & $0.28^{\mathrm{b}}$ & $0.33^{b}$ \\
\hline$\Delta R^{2}$ & & 0.00 & & $0.05^{b}$ \\
\hline
\end{tabular}

explains the failure of the ECT component (containing both overclaiming and IT scores) in the top of Table 3. On the other hand, the over-claiming task added incremental validity $(\beta=0.271)$ to the prediction of MBA exam scores. The change in variance explained here at step 2 (i.e., $4 \%$ ) was also significant. Hence, in three of four cases, the ECTs added incremental validity to prediction of MBA grades and MBA capstone exam scores.

\section{Discussion}

Hypotheses 1 and 2 were generally supported, based on the following key results: (1) The IT and over-claiming ECTs correlated significantly with both MBA grades and the capstone exam. So, too, did a component score derived from the ECT variables. (2) A median split on the ECT component score showed consistent and moderate-to-large differences on grades and exam scores. The best-performing ECT group had higher grade point averages and scored better on the MBA exam (they also scored higher on both the GMAT and WPT). (3) The IT task showed incremental validity over IQ and GMAT scores for both grades and capstone exam scores. (4) The over-claiming task produced incremental validity for the exam scores, but not for MBA grades.
The failure of the over-claiming task to uniquely predict grades could be because the task is verbal-based, and thus shared common method variance with both the WPT and the GMAT. Unlike the over-claiming task, IT seems to possess little in common with either standardized exam. Yet how well students judged line lengths predicted both their grades and their capstone exam scores. Speed of information intake, as measured by the IT task, seems to be an important individual difference. Here it improved the prediction accuracy of a high-level outcome (i.e., student performance in an MBA program), even after factoring in performance on standardized test scores like the GMAT and the WPT. In this regard, our results are similar to those reported by Luo et al. (2006: see also Rohde \& Thompson, 2007).

The size of the ECT validity coefficients found here (0.24-0.50) are not far off those reported in meta-analysis for the GMAT predicting MBA grades $(0.31 ; 0.47$ when corrected for attenuation; Kuncel, Crede, \& Thomas, 2007), or for the WPT predicting undergraduate grades (0.30-0.45; McKelvie, 1989). At a practical level, the ECTs required less than 10 min per student to administer, but returned about a $5 \%$ increase in variance explained over and above the WPT and GMAT. Future research might explore whether ECTs predict performance in other real-world settings (e.g., job performance).

Theoretically, ECTs might predict student success for the same reason general mental ability predicts job success (for example). As measures of basic cognition, ECTs could reflect individual differences in the amount and rate of knowledge students will acquire in graduate school. "Management knowledge" (like job knowledge, see, e.g., Hunter, 1993; Schmidt, Hunter, \& Outerbridge, 1986) might then serve to mediate the relationship between ECT and school performance. This is an empirical question in need of future research.

Limitations to the present study include a relatively small sample size, which reduced power and prohibited testing hypotheses at the latent level with structural equation models. In most cases, however, key measures significantly predicted their criterion. Nonetheless, studies with larger samples could model the effects of information processing ability on school performance in a more theoretically meaningful way. Second, future researchers might use a more robust battery of tests to capture information processing ability. Here, we used only two ECTs, one of which in hindsight likely shared too much in common with both the WPT and the GMAT. A larger battery of ECTs and score aggregation might produce even stronger effects than those reported here.

In conclusion, the present study shows that ECTs possess criterion validity for predicting student performance in an MBA program. ECTs also possess incremental validity-especially in the case of the IT task-over IQ and GMAT scores. Specifically, the ability to judge the lengths of rapidly-presented lines explained nontrivial variance in both grades and capstone exam scores. The present data offer further justification for the use of ECTs as predictors of real-world outcomes.

\section{References}

Burns, N., \& Nettelbeck, T. (2002). Inspection time in the structure of cognitive abilities: Where does IT fit. Intelligence, 31, 237-255.

De Pascalis, V., Varriale, V., \& Matteoli, A. (2007). Intelligence and P3 components of the event-related potential elicited during an auditory discrimination task with masking. Intelligence, 36, 35-47.

Frey, M., \& Detterman, D. (2004). Scholastic assessment or $g$ ? The relationship between the scholastic assessment test and general cognitive ability. Psychological Science, 15, 373-378.

Geisinger, K. (2001). Review of the wonderlic personnel test and scholastic level exam. In B. S. Plake \& J. C. Impara (Eds.), The fourteenth mental measurements yearbook (pp. 1360-1363). Lincoln, NE: Lincoln.

Gottfredson, L. (2004). Schools and the g factor. The Wilson Quarterly(Summer), $35-45$. 
Grudnik, J., \& Kranzler. J. (2001). Meta-analysis of the relationship between intefligence and inspection time. Intelligence, 29, 523-535.

Haier, R., Siegel, B., Tang, C., Abel, L., \& Buchsbaum, M. (1992). Intelligence and changes in regional cerebral glucose metabolic rate following learning. intelligence, $16,415-426$.

Hasher, L., \& Zacks, R. T. (1979). Automatic and effortful processes in menory. Journal of Experimental Psychology: General, 108, 356-388.

Hunter. J. (1993). A causal model of cognitive ability. job knowledge, job performance, and supervisor ratings. In F. J. Landy, S. Zedeck, \& J. Cleveland (Eds.), Performance measurement and theory (pp. 257-266). Hillsdale, NJ: Lawrence Erlbaum.

Jacoby, L. (1992). A process dissociation framework: Separating automatic from intentional uses of memory. Journal of Memory and Language, 30, 513-541.

Jensen, A. (1998). The $g$ factor: The science of mental ability. Westport, CT: Praeger.

Jensen, A. (2006). Clocking the mind: Mental clironometry and individual differences. Amsterdam, The Netherlands: Elsevier.

Koenig, K., Frey, M., \& Detterman, D. (2008). ACT and general cognitive ability. Intelligence, $36,153-160$

Kranzler, J., \& Jensen, A. (1989). Inspection time and intelligence: A meta-analysis. Intelligence, 13, 329-347.

Kuncel, N., Crede, M., \& Thomas, L. (2007). A meta-analysis of the predictive validity of the graduate management admission test (GMAT) and undergraduate grade point average (UGPA) for graduate student academic performance. Academy of Management Learning and Education, 6, 51-68.

Luciano, M., Leisser, R., Wright, M.. \& Martin. N. (2004). Personality, arousal theory, and the relationship to cognitive ability as measured by inspection time and IQ Personalicy and Individual Differences, 37, 1081-1089.

Luo, D., Thompson, L. \& Detterman, D. (2006). The criterion validity of tasks of basic cognitive processes. Intelligence, 34, 79-120.

McDaniel, M. (2005). Big-brained people are smarter: A meta-analysis of the relationship between in-vivo brain volume and intelligence. Intelligence, 33 . 337-346.
McKelvie, S. (1989). The wonderlic personnel test: Reliability and validity in an academic setting. Psychological Reports, 65, 161-162.

Neisser, U., Boodoo, G., Bouchard, T., Boykin, W., Brody, N., Ceci, S., et al. (1996) Intelligence: Knowns and unknowns. American Psychologist, 51, 77-101.

Paulhus, D., \& Harms, P. (2004). Measuring cognitive ability with the over-claiming technique. Intelligence, 32, 297-314.

Pesta, B., \& Poznanski, P. (2008). Black-white differences on IQ and grades: The mediating role of elementary cognitive tasks. Intelligence, 36, 323-329.

Posthuma, D.. Geus, E., Baare, W., Pol, H., Kahn, R., \& Boomsma, D. (2002). The association between brain volume and intelligence is of genetic origin. Nature Neuroscience, 5(2), 83-84.

Prokosch, M., Yeo, R. \& Miller, G. (2005). Intelligence tests with higher g-loadings show higher correlations with body symmetry: Evidence for a general fitness factor mediated by developmental stability. Intelligence, 33, 203-213.

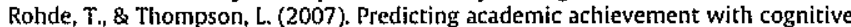
ability. Intelligence, 35, 83-92.

Schmidt, F., \& Hunter, J. (1998). The validity and utility of selection methods in personnel psychology: Practical and theoretical implications of 85 years of research findings. Psychologica! Bulletin, 124, 262-275.

Schmidt, F., Hunter. J., \& Outerbridge. A. (1986). Impact of job experience and ability on job knowledge, work sample performance, and supervisory ratings of job performance. Journat of Applied Psychology, 71, 432-439.

Sheppard, L., \& Vernon, P. (2008). Intelligence and speed of information-processing: A review of 50 years of research. Personality and Individual Differences, 44, 535-551.

Williams, K., Paulhus, D., \& Nathanson, C. (2002). The nature of over-claiming: Personality and cognitive factors. Poster presented at the 110 th annual meeting of the American psychological association, Chicago. IL. [August, 2002].

Wonderlic \& Associates (2002). Wonderlic personnel test manual. Libertyville, IL: Wonderlic.

Yonelinas, A., \& Jacoby, L. (1996). Noncriterial recollection: Familiarity as automatic irrelevant recollection. Consciousness and Cognition, 5, 131-141. 